\title{
BMJ Open What do people with lung cancer and stroke expect from patient navigation? A qualitative study in Germany
}

\author{
Hella Fügemann (D) , ${ }^{1,2}$ Ute Goerling, ${ }^{3}$ Kathrin Gödde, ${ }^{1}$ Anke Kristin Desch, ${ }^{1,2}$ \\ Jacqueline Müller-Nordhorn, ${ }^{4}$ Verena Mauckisch, ${ }^{1}$ Bob Siegerink, ${ }^{5}$ \\ Nina Rieckmann, ${ }^{1}$ Christine Holmberg (iD ${ }^{1,2,6}$
}

To cite: Fügemann $\mathrm{H}$, Goerling U, Gödde K, et al. What do people with lung cancer and stroke expect from patient navigation? A qualitative study in Germany. BMJ Open 2021;11:e050601. doi:10.1136/ bmjopen-2021-050601

- Prepublication history and additional supplemental material for this paper are available online. To view these files, please visit the journal online (http://dx.doi.org/10.1136/ bmjopen-2021-050601).

Received 26 February 2021 Accepted 03 November 2021

Check for updates

(C) Author(s) (or their employer(s)) 2021. Re-use permitted under CC BY-NC. No commercial re-use. See rights and permissions. Published by BMJ.

For numbered affiliations see end of article.

Correspondence to Mrs Hella Fügemann; hella.fuegemann@charite.de

\section{ABSTRACT}

Objective This qualitative study investigated patients' needs and wishes in relation to patient navigation. Design A qualitative interview study was conducted. Participants were invited to take part in three in-depth interviews over a period of 6-12 months. Thematic analysis was used.

Setting Interviewees were sought in the Berlin metropolitan area of Germany in academic university hospitals, in rehabilitation clinics and through self-help organisations.

Participants The sample consisted of individuals diagnosed with lung cancer $(n=20)$ or stroke $(n=20)$. Results From the perspective of interviewees, patient navigators should function as consistent contact persons, present during the whole care trajectory. Their role would be to guide patients through an often confusing healthcare landscape, offering practical, advisory and emotional assistance corresponding to patients' needs. The study shows that-independent of the disease-participants had similar expectations and needs regarding support from navigators.

Conclusion For chronic and complex diseases-as is the case with lung cancer and stroke-it appears less important for navigators to fulfil disease-specific tasks. Rather, they should ensure that patients' more general needs, in relation to social, practical and emotional support, are met in a way that suits their individual wishes. Following these results, patient navigation programmes might be designed to include generic elements, which should then be adapted to the infrastructure in a particular healthcare region and to the particularities of a specific healthcare system.

\section{INTRODUCTION}

The demographic development towards an ageing society represents one of the greatest challenges to healthcare systems in industrialised countries worldwide, including Germany. Age-related diseases such as cancer and stroke have either stagnated at high levels or will continue to rise in the coming decades. ${ }^{1-4}$ Additionally, because medicine is continuously differentiating into further specialities, healthcare for older adults and
Strengths and limitations of this study

- Interviewees had diverse backgrounds in terms of disease and treatment experiences, including acute and chronic disease care.

- The implementation of in-depth interviews over time permits a comprehensive and multifaceted collection of knowledge regarding the expectations and support needs of patients in relation to navigation.

- The sample comprises only participants from a single metropolitan region in Germany-support needs and expectations regarding patient navigation may be different in rural areas or indeed elsewhere in the world.

people with chronic diseases is becoming ever more complex and it is becoming more difficult to ensure coordinated, consistent care across all sectors. ${ }^{5-8}$ This trend is exacerbated by the German healthcare system that traditionally has a distinct separation of outpatient and inpatient care, with no coordination along a patient's care trajectory between these different care sectors. ${ }^{68-10}$

These challenges have led to the development of patient navigation programmes in several countries. ${ }^{11-15}$ Patient navigation has been suggested as a model for care delivery for complex and chronic health conditions in particular, to guide patients as they handle increasingly complex healthcare systems or treatment regimens. ${ }^{1114}$ The model of patient navigation was originally developed in the USA to improve and expedite access to healthcare for vulnerable populations and minorities after an abnormal screening finding or a cancer diagnosis. ${ }^{16}$ Since then, many patient navigation models, which are quite diverse with regard to navigator characteristics and programme structure, have been developed for different patient populations. ${ }^{17}$ Common navigation tasks include the provision of information, guidance, advocacy, emotional 
and practical support, as well as education and empowerment. ${ }^{11}{ }^{18-20}$ Patient navigation aims to support patients to organise their healthcare according to their individual needs and to optimise their care trajectory. ${ }^{13} 1421-25$

Patient navigation programmes may be particularly well suited to overcoming the shortcomings in the German system. In order to investigate such an assumption, we carried out a qualitative interview study to investigate patients' needs in relation to navigation programmes. To be able to assess needs across a spectrum of diseases that are particularly relevant in older age groups, we selected lung cancer (LC) and stroke. We used these two diseases as prototypical examples of age-associated chronic diseases with very different progressions; additionally, the number of cases for both diseases in Germany is high. ${ }^{3}$ Both LC and stroke are characterised by often very complex healthcare needs and we therefore view them as particularly suitable for patient navigation. The two diseases are, furthermore, characterised by different trajectories with very different impacts on patients' lives. ${ }^{26}{ }^{27}$ This ensures that a broad range of diverse needs can be captured when developing a navigation model for Germany. Patients with LC face a low 5-year survival rate and may experience rapidly deteriorating health with aggressive treatments and regular visits during ambulatory care ${ }^{25}{ }^{28} \mathrm{~A}$ palliative care situation may arise early after diagnosis. In contrast, patients who have experienced a stroke often face longterm consequences in everyday life, including new social care and support needs, while co-morbidities are common. ${ }^{29}{ }^{30}$ In addition to direct medical care, studies show that patients with age-associated chronic diseases often have a further need for social work and administrative and informational support when handling their new health and living situation. ${ }^{31-33}$

In this article, we present patients' views on navigation, with the aim of understanding the kinds of support people with LC and stroke want from navigators, and what requirements such a care model should fulfil from their point of view.

\section{METHODS}

\section{Study design}

A longitudinal, qualitative interview study was conducted in the metropolitan region of Berlin, Germany. Participants were invited to take part in three in-depth interviews: at baseline, after 3 months and after 6 months for patients with LC, and at baseline, after 6 months and after 12 months for patients with stroke. We chose shorter intervals between follow-up interviews with participants with LC because they were expected to experience a more rapid deterioration in health than participants with stroke. Patient eligibility criteria included being aged 18 years or older, having a diagnosis of LC or stroke, having sufficient command of the German language, and being physically and mentally willing and able to complete the interviews. Purposeful sampling was used to achieve a diverse sample of patients who were likely to have different experiences in the healthcare system. Selection was based on age, gender, time since diagnosis, comorbidities and selected treatments. Demographic variables were collected via a self-report questionnaire before each interview. Sixteen persons with LC (of 20 at baseline) and 18 persons with stroke (of 20 at baseline) also completed the first follow-up interview $(\mathrm{n}=34)$. We present results from the baseline and first follow-up interviews, because these were the two interviews (out of three) when participants had the possibility to express their own ideas and wishes for a patient navigation programme.

\section{Recruitment}

Patients with LC were recruited at the LC outpatient clinic of a large academic university hospital in the Berlin metropolitan region and through self-help groups and the psycho-oncological department of the comprehensive cancer centre of the university hospital between December 2017 and May 2019. Patients with stroke were recruited from neurological units of the university hospital and in different rehabilitation clinics between January 2018 and October 2018. Potential participants were approached personally by study personnel. All participants provided written informed consent before participating in the interview study.

\section{Data collection}

Baseline interviews were conducted from December 2017 to April 2019, and the two follow-up interviews were completed by November 2019. These face-to-face interviews were conducted in German and at a place convenient for the patients (at their home, at the LC outpatient clinic, in rehabilitation clinics, in the researcher's office). The interviews lasted on average between 60 and $90 \mathrm{~min}$, and were audiorecorded and transcribed verbatim. Any identifying details were removed and participants were assigned pseudonyms. The in-depth interviews at baseline and first follow-up had a section focusing on expectations, suggestions and support needs regarding patient navigation. In the baseline interviews, study participants were asked to describe their own ideas of navigation and navigators, if possible without any previous explanation of the concept of navigation. In the first follow-up interviews, questions focused on specific aspects of navigation, that is, the mode and structure of interactions with navigators, the tasks of navigators, and participants' ideas of the target groups for navigation. We used primarily openended questions in the interviews so that participants had the opportunity to speak freely and openly about what was important to them in their care, including positive and negative experiences with healthcare. Interview questions from the baseline and first follow-up interviews regarding patient navigation are presented in online supplemental table 1 .

\section{Analysis}

To capture study participants' views on navigation, most importantly on the kind of support they were looking 
for from a navigator, we used a descriptive qualitative approach. ${ }^{34-36}$ In a first step, we identified all answers to the following questions from the interview guide that asked about navigation: what do participants imagine is meant by the term navigator, what kind of tasks should navigators fulfil and how should interactions take place from their point of view (see also online supplemental table 1). We then coded the data corpus according to deductive codes: Patients' definition of navigators, tasks of navigators, communication and interaction modes, and target groups. ${ }^{11} 18$ These predefined codes were chosen to fill core components of the navigation programme with content based on patients' wishes and ideas (see online supplemental table 2). Then the text passages under each code were used for inductive, thematic analysis. This analysis was done separately for both patient groups and then compared with each other in order to condense content of the deductive codes. Similarities in content across codes between both data sets became apparent. After finalising the thematic content of each deductive code, components of a navigation model were defined in line with the inductive thematic analysis. ${ }^{37} 38$ In this process, initial deductive codes were renamed when necessary to align them with interviewees' views and wishes (see online supplemental table 2). The entire analysis process was conducted by $\mathrm{HF}$ and $\mathrm{CH}$ through regular data session meetings to discuss the data material and determination of codes and categories. Additionally, the analysis process and the data itself were presented and discussed regularly within a qualitative research group at the Charité-Universitätsmedizin Berlin to ensure grounding of analysis in the data throughout. In these research meetings, coding was scrutinised by reading the coded text passages and discussing the associated code and its fitness.

\section{Patient and public involvement}

Representatives of self-help groups (LC and stroke) were regularly invited to participate in our project meetings to consult on the research questions and to identify existing resources and gaps in the healthcare system.

\section{RESULTS}

\section{Participants' demographic characteristics}

The sample consisted of 20 patients with LC and 20 patients with stroke at baseline $(n=40)$. Individuals with LC included 12 women and 8 men. For the baseline survey, patients were between 44 and 75 years old. Patients with stroke (S) included 9 women and 11 men, and at the time of the first interview they were between 41 and 81 years old. The demographic characteristics of the participants are summarised in tables 1 and 2. Reasons for drop-out after baseline were severe progression of the disease ( $L C=3 ; S=1)$ or the death of patients $(L C=1 ; S=1)$.

\section{Expectations and support needs}

The results pertaining to the interviewed patients' ideas and support needs regarding navigators were similar for
Table 1 Participants' sociodemographic characteristics at baseline interview (lung cancer)

Patients with lung cancer $(n=20)$

\begin{tabular}{|lr|}
\hline Gender & \\
Male & 8 \\
Female & 12 \\
\hline
\end{tabular}

Age in years

$\begin{array}{ll}41-50 & 3 \\ 51-60 & 8 \\ 61-70 & 6 \\ 71-80 & 3 \\ \text { Time since diagnosis } & \\ 1-6 \text { months } & 5 \\ 7-12 \text { months } & 5 \\ 1-2 \text { years } & 4 \\ 2-5 \text { years } & 4 \\ >5 \text { years } & 2 \\ \text { Health insurance status } & \\ \text { Statutory } & 16 \\ \text { Private } & 4\end{array}$

Marital status

$\begin{array}{lr}\text { Single } & 1 \\ \text { Married/living with partner } & 15 \\ \text { Divorced } & 3 \\ \text { Widowed } & 1 \\ \text { Household size (persons) } & \\ 1 & 5 \\ 2 & 11 \\ 3 & 4\end{array}$

Education

$\begin{array}{lr}\text { University degree } & 4 \\ \text { Polytechnic degree } & 3 \\ \text { Training } & 12 \\ \text { No vocational training } & 1 \\ \text { Employment status } & \end{array}$

Employment status

$\begin{array}{lc}\text { Employee or official } & 5 \\ \text { Pensioner } & 7 \\ \text { Early retirement/disability pension } & 5 \\ \text { Unemployed } & 1 \\ \text { Self-employed } & 1 \\ \text { Housewife } & 1 \\ \text { Current treatment } & \\ \text { Inpatient } & 0 \\ \text { Outpatient } & 20 \\ \text { Comorbidities } & \\ \text { Yes } & 12 \\ \text { No } & 8\end{array}$


Table 2 Participants' sociodemographic characteristics at baseline interview (stroke)

\begin{tabular}{lc}
\hline & Patients with stroke $(\mathbf{n = 2 0})$ \\
\hline Gender & \\
Male & 11 \\
Female & 9
\end{tabular}

\begin{tabular}{|c|c|}
\hline \multicolumn{2}{|l|}{ Age in years } \\
\hline $41-50$ & 3 \\
\hline $51-60$ & 7 \\
\hline $61-70$ & 5 \\
\hline $71-80$ & 4 \\
\hline $81-90$ & 1 \\
\hline \multicolumn{2}{|c|}{ Time since diagnosis } \\
\hline $1-6$ months & 15 \\
\hline $7-12$ months & 1 \\
\hline $1-3$ years & 4 \\
\hline
\end{tabular}

Health insurance status

\begin{tabular}{|lc|}
\hline Statutory & 19 \\
\hline Private & 1 \\
\hline Marital status & \\
\hline Single & 3 \\
\hline Married/living with partner & 7 \\
\hline Married but separated & 2 \\
\hline Divorced & 5 \\
\hline Widowed & 2 \\
\hline n/a & 1 \\
\hline
\end{tabular}

Household size (persons)

\begin{tabular}{|cc|}
\hline 1 & 8 \\
\hline 2 & 9 \\
3 & 2 \\
\hline 4 & 1 \\
\hline Education & \\
\hline University degree & 2 \\
\hline Polytechnic degree & 4 \\
\hline Training & 11 \\
\hline No vocational training & 2 \\
\hline n/a & 1 \\
\hline Employment status & \\
\hline Employee or official & 4 \\
\hline Pensioner & 8 \\
\hline Early retirement/disability pension & 3 \\
\hline Unemployed & 3 \\
\hline n/a & 2 \\
\hline Current treatment & 9 \\
\hline Inpatient & 11 \\
\hline Outpatient & 9 \\
\hline Comorbidities & \\
\hline Yes & 11 \\
\hline No & 9 \\
\hline
\end{tabular}

$\mathrm{n} / \mathrm{a}$, not available. both diseases. Overarching categories were patients with support needs, tasks and support needs, and role of navigators. The deductive code target groups was changed to the overarching category patients with support needs because inductive thematic analysis showed who-from study participants' point of view-urgently needed help and support from navigators. This included primarily older individuals and/or those with impairments, but also patients without a social network, and patients' relatives or informal caregivers. The code tasks of navigators was renamed to the overarching category tasks and support needs because the thematic analysis showed that from the patients' perspective these two things belong together thematically. The overarching category tasks and support needs refers to all combined desires and expectations that the interviewed patients could imagine as supportive; for example, the wish for information, for help in coordinating their care as well as for bureaucratic issues. Patients could also envisage pursuing leisure activities together with the navigator. Emotional support in the form of 'having someone to talk to' was also mentioned. After the thematic analysis, the deductive codes patients' definition of navigators and communication and interaction modes were merged into one overarching category named role of navigators. This overarching category describes how and where navigators could be best integrated into the healthcare structure. Above all, patients wished for navigators to be available as a consistent, long-term contact person, that they should not have to travel long distances or make additional efforts to meet their navigator, and that there would be no conflict with other participating professional caregivers. Interview quotes illustrating each particular theme and category can be found in tables $3-5$.

\section{Patients with support needs}

When asked who, in their view, had a more urgent need for a navigator, patients mentioned various groups, including older people and/or individuals with impairments, but also patients without a social network and patients' relatives or informal caregivers. They tended to outline fewer of their own experiences, and rather referred to other patients whom they had observed during the course of their disease. The interviewed patients agreed that the use of a navigator might be valuable, though not all of them would use a navigator themselves; for example, because they felt adequately cared for within their own social network.

Patients who are elderly or have physical/cognitive impairments According to the interviewees, older patients, but also persons who, for example, have impaired mobility or cognitive limitations after a stroke, would have a particularly urgent need for a navigator.

\section{Patients without a social network}

The interviews show that patients without a supportive social network appear to have a particularly difficult time organising their care; either because they are 
Table 3 Characteristic quotations from the interviews illustrating the overarching category patients with support needs

\begin{tabular}{|c|c|c|}
\hline $\begin{array}{l}\text { Overarching } \\
\text { category }\end{array}$ & Codes & Quotes \\
\hline \multirow[t]{4}{*}{$\begin{array}{l}\text { Patients } \\
\text { with support } \\
\text { needs }\end{array}$} & $\begin{array}{l}\text { Patients who } \\
\text { are elderly or } \\
\text { have physical/ } \\
\text { cognitive } \\
\text { impairments }\end{array}$ & $\begin{array}{l}\text { Because many people who are older are discharged from the hospital and no one worries about whether they } \\
\text { are eating, or cared for, right? So, all of that gets lost somewhere. } \\
\text { (LC, f, 50-60 years, diagnosis more than } 10 \text { years ago) } \\
\text { For example, those individuals sitting in a wheelchair or who actually have memory difficulties. } \\
\text { (S, m, 50-60 years, diagnosis less than } 1 \text { year ago) }\end{array}$ \\
\hline & $\begin{array}{l}\text { Patients without } \\
\text { a social network }\end{array}$ & $\begin{array}{l}\text { Exactly. I do that all by myself. I had to do everything alone. All of the applications that I had to make. For } \\
\text { example, I should now have to apply for unemployment money here, so as not to be caught short. That is } \\
\text { nerve-racking for me, to tell the truth. And no one provides the information on their own, what you can apply } \\
\text { for, what is available to you. } \\
\text { (S, f, } 40-50 \text { years, diagnosis less than } 1 \text { year ago) } \\
\text { First, I need to see how I can even get a phone number. Life needs to keep going somehow. I need to get the } \\
\text { therapy somehow, that is surely important. But I don't know, I have no phone number or anything. It is difficult } \\
\text { now. I am more or less at home now for the first day. That is, without help I am a bit beat. I am more or less } \\
\text { reliant on family or the hospital now. That is my external world. Otherwise there is no one around who takes } \\
\text { care of things and worries about me. } \\
\text { (S, m, } 60-70 \text { years, diagnosis less than } 1 \text { year ago) } \\
\text { For example, for single persons. Then such a thing would be absolutely recommendable. That there is some } \\
\text { reaching out in support. Many people in this case are entirely alone. And I think that is independent of age. } \\
\text { (LC, m, } 50-60 \text { years, diagnosis less than } 1 \text { year ago) }\end{array}$ \\
\hline & $\begin{array}{l}\text { Relatives } \\
\text { and informal } \\
\text { caregivers }\end{array}$ & $\begin{array}{l}\text { But that anyway, maybe someone will also include the relatives. Perhaps also make a phone call once in a } \\
\text { while. } \\
\text { (LC, } \mathrm{f}, 60-70 \text { years, diagnosis less than } 5 \text { years ago) } \\
\text { No, he [the husband] was not at all in a position to manage. He did not know at all what he should attend to. } \\
\text { (S, f, 60-70 years, diagnosis less than } 1 \text { year ago) }\end{array}$ \\
\hline & No needs & $\begin{array}{l}\text { I don't know at the moment what someone external could do for me. Because what everyone can do is } \\
\text { allocated. } \\
\text { (LC, f, 60-70 years, diagnosis less than } 1 \text { year ago) } \\
\text { But otherwise, taking me by the hand and such, no. Until now I have everything together, I think. After all, I } \\
\text { didn't fall on my head. In that sense, that someone is constantly telling me what to do, I am not in favour of } \\
\text { that. } \\
\text { (LC, m, } 70-80 \text { years, diagnosis less than } 1 \text { year ago) } \\
\text { I do not need it, thank God, I do not need it. Those people who really rely on it, they should use it then. } \\
\text { (S, f, } 60-70 \text { years, diagnosis less than } 1 \text { year ago) }\end{array}$ \\
\hline
\end{tabular}

overwhelmed by the number of tasks they find themselves presented with, or lack the necessary knowledge, resources or competencies to arrange for their care. Study participants described this based on both their own experiences as well as on observations of other patients. Patients with support from their social network perceived less need for support from professional navigators for themselves.

\section{Relatives and informal caregivers}

The offer of support by navigators should, from the interviewees' point of view, also be available to relatives and informal caregivers. Patients had the feeling that, in the current system, relatives and informal caregivers have too little support and are not adequately integrated into the caregiving procedure. Interviewees were aware of the burden that the disease presents for relatives and informal caregivers and that they can feel partially helpless.

\section{No needs}

The interviews show that not all of the study participants had a need for or would like a navigator. The reasons for this were, for example, that all tasks had already been assigned, that the interviewees would rather control the situation themselves, or that they thought other patients would need a navigator more than they did.

\section{Tasks and support needs}

This category refers to the wishes for and expectations of support that participants could imagine. In the interviews, five topics could be identified as particularly important to the participants: the wish for consultation and information, the need for help with organising and coordinating care, support with bureaucratic and administrative obstacles, help with housekeeping and leisure activities, and the wish for emotional support.

\section{Consultation and information}

The study participants clearly placed an emphasis on consultations and the relaying of information-whether very generally pointing out opportunities for support or specifying consultations on particular topics such as social issues, social regulations and financial topics, but also, for example, related to sports and nutrition. They would find it very valuable to obtain all of this information from one source and not to have to tediously gather it by themselves. 
Table 4 Characteristic quotations from the interviews illustrating the overarching category tasks and support needs

\begin{tabular}{|c|c|c|}
\hline $\begin{array}{l}\text { Overarching } \\
\text { category }\end{array}$ & Codes & Quotes \\
\hline \multirow[t]{4}{*}{$\begin{array}{l}\text { Tasks and } \\
\text { support } \\
\text { needs }\end{array}$} & $\begin{array}{l}\text { Consultation } \\
\text { and information }\end{array}$ & $\begin{array}{l}\text { That they [navigators] sort of show the patient where things are headed and what needs to be considered. } \\
\text { Someone who will explain exactly where they can ask for something and where they can obtain financial } \\
\text { support. } \\
\text { (LC, f, } 50-60 \text { years, diagnosis less than } 1 \text { year ago) } \\
\text { That would be helpful: an office where you could get all of this information as a stroke patient. } \\
\text { (S, f, } 40-50 \text { years, diagnosis less than } 1 \text { year ago) } \\
\text { There is much one doesn't know. And you have to worry about everything yourself. And it shouldn't be like } \\
\text { that. } \\
\text { (S, } \mathrm{m}, 50-60 \text { years, diagnosis less than } 1 \text { year ago) }\end{array}$ \\
\hline & $\begin{array}{l}\text { Organisation } \\
\text { and } \\
\text { coordination }\end{array}$ & $\begin{array}{l}\text { That the [navigator] perhaps phones or tries to obtain phone numbers from a certain physician or makes } \\
\text { appointments. They can look in their computer for that, to see when there are openings. Because not everyone } \\
\text { has a computer, like me for example. } \\
\text { (S, m, } 60-70 \text { years, diagnosis less than } 1 \text { year ago) } \\
\text { That they [navigators] at least have a few addresses or contact persons to whom you can turn, and perhaps } \\
\text { they could also be a type of liaison. } \\
\text { (LC, m, } 50-60 \text { years, diagnosis less than } 1 \text { year ago) } \\
\text { But if you have someone, an actual contact person, a sort of coordinating person, a person to address, I think } \\
\text { that this would be very helpful to patients. Just someone who can be reached when needed. Where one also } \\
\text { has an offer for organisation, so to say. } \\
\text { (LC, m, } 40-50 \text { years, diagnosis between } 1 \text { and } 5 \text { years ago) }\end{array}$ \\
\hline & $\begin{array}{l}\text { Support with } \\
\text { bureaucracy }\end{array}$ & $\begin{array}{l}\text { For all of the applications. Because all of this paperwork, that is my weakness. } \\
\text { (S, m, 50-60 years, diagnosis less than } 1 \text { year ago) } \\
\text { That is, when you are totally alone, to really fight your way through, so to speak. As I said, as I saw it last } \\
\text { summer, when I was just overwhelmed with the entire stuff. I am not going to fill in any application then. } \\
\text { (LC, m, 40-50 years, diagnosis between } 1 \text { and } 5 \text { years ago) }\end{array}$ \\
\hline & $\begin{array}{l}\text { Help with } \\
\text { housekeeping/ } \\
\text { leisure } \\
\text { activities }\end{array}$ & $\begin{array}{l}\text { These are issues that are very banal for me: making beds, putting things together, hanging things up. Or going } \\
\text { for a little stroll. } \\
\text { (S, f, } 50-60 \text { years, diagnosis between } 1 \text { and } 5 \text { years ago) } \\
\text { For example, shopping could be done... And then I would also like to go to the soccer stadium. And I watch } \\
\text { the game, that person drives me back. Would be quite nice. Or simply go to the movies, then back again. } \\
\text { (LC, m, 60-70 years, diagnosis between } 1 \text { and } 5 \text { years ago) }\end{array}$ \\
\hline
\end{tabular}

\section{Organisation and coordination}

A further important area of activity that interviewees saw for navigators was the organisation and coordination of their care; for instance, in the form of support to make appointments with physicians and therapists. The endless phone calls required to arrange outpatient care was especially criticised in the interviews. Additionally, not all study participants had a computer and it became obvious how difficult it is in this case to even find the address of potential caregivers. In this regard, the assistance of navigators-by contacting caregivers for patients or directly relaying existing support opportunities-was viewed as potentially very helpful.

\section{Support with bureaucracy}

Bureaucracy was a big topic for the patients interviewed. They wished to have consultation and support when filling in forms and applications, such as for rehab, pensions, cost coverage, etc. It was these administrative issues in particular that the interviewees described as additional obstacles and burdens, on top of their serious disease; this was especially the case for those without social support.

\section{Help with housekeeping/leisure activities}

Some study participants also named tasks in the area of housekeeping and leisure time. Especially for those with limited mobility or patients weakened by therapy, dealing with housekeeping (shopping, making beds, etc) was a topic. Leisure activities, such as going to a soccer game or taking a walk, were also mentioned as something that could be conducted together with a navigator.

\section{Emotional support}

Interviewees had the expectation that navigators could offer them and their families emotional support by responding to emotional distress, listening supportively and providing comfort. They expressed the desire to have someone such as a navigator at their side, who would care for them as a human being and who would regularly ask about how they feel and how things are going. Some study 
Table 5 Characteristic quotations from the interviews illustrating the overarching category role of navigators

\begin{tabular}{|c|c|c|}
\hline $\begin{array}{l}\text { Overarching } \\
\text { category }\end{array}$ & Codes & Quotes \\
\hline \multirow[t]{2}{*}{$\begin{array}{l}\text { Role of } \\
\text { navigators }\end{array}$} & $\begin{array}{l}\text { Consistent } \\
\text { and long- } \\
\text { term contact } \\
\text { person who } \\
\text { has time }\end{array}$ & $\begin{array}{l}\text { Because it is difficult with the contact persons that you usually have, who are always changing. Here a } \\
\text { doctor, there a doctor. There just doesn't seem to be a fixed contact person. } \\
\text { (LC, f, 50-60 years, diagnosis less than } 1 \text { year ago) } \\
\text { Sure, having a contact person with time and the inclination, yes? So that you don't get the feeling that } \\
\text { you are bothering them. But rather someone who takes the time and is concerned with the anxieties and } \\
\text { questions that the patient has. } \\
\text { (S, f, 70-80 years, diagnosis less than } 1 \text { year ago) }\end{array}$ \\
\hline & $\begin{array}{l}\text { Flexible } \\
\text { mode of } \\
\text { interaction } \\
\text { and outreach }\end{array}$ & $\begin{array}{l}\text { For me, in my case, depending on need. If I had a problem I would very gladly reach out to them (the } \\
\text { navigators). } \\
\text { (S, } \mathrm{f}, 40-50 \text { years, diagnosis less than } 1 \text { year ago) } \\
\text { If you are feeling that bad, then you surely would wish that someone would come and approach you. } \\
\text { (LC, f, 60-70 years, diagnosis between } 1 \text { and } 5 \text { years ago) } \\
\text { I think there are few who would dare to request this. I think that if someone approaches from the outside, } \\
\text { the reaction is different from when you have to be active externally. First of all, you don't know where to } \\
\text { go, and then the problems already start. Who do you call? That is, it has to come from outside. } \\
\text { (S, f, 60-70 years, diagnosis less than } 1 \text { year ago) }\end{array}$ \\
\hline
\end{tabular}

participants stated that they would appreciate the presence of navigators to help combat loneliness.

\section{Role of navigators}

Participants wished for navigators to be available as consistent contact persons along their entire care trajectory. A navigator programme would require a high level of flexibility in regard to delivery mode or interaction intervals from patients' perspectives and should be implemented within existing care structures in order to be easily reachable for patients.

\section{Consistent and long-term contact person who has time}

Study participants expressed the desire for a consistent contact person who would have time for them, and who would be available along their entire care trajectory. In their view, there was no one who had an overview of their care history and who could hold together the threads that made up their care. They envisaged that navigators could fill this gap, in that they could be available for patients as early as diagnosis and would act as a regular contact person during the course of the care trajectory. An important aspect would be that the navigators would not have any time pressure, as is the case for many other caregivers in the healthcare system, but would rather be able to take enough time for each individual patient.

\section{Flexible mode of interaction and outreach}

A strongly emphasised request was that, in the interaction with the navigator, there should be consideration for patients' individual needs. Study participants wished to have the opportunity to be able to reach the navigator flexibly and through various communications channels, including phone, email, in person, etc. Home visits were also mentioned, such as for those with mobility impairments or for patients who have been weakened by treatment. Interviewees also considered it important that navigators would not only be available at agreed appointment times, but sometimes also on short notice, such as for acute questions or problems, and without great obstacles. Regarding the offer of possible support from navigators, many study participants said that they would like to be informed proactively; that is, they would like to have someone actively approach them and offer support, rather than having to search for help themselves. Others reported that the question of whether they would like to be proactively contacted by a navigator, or rather reach 
out to a navigator themselves, would depend on their health status.

\section{Integration into existing healthcare structures}

Interviewees requested that they should not have to travel long distances or make additional efforts to meet their navigator in person. Rather, these meetings would optimally take place at the same location as their therapy. It was also important to many study participants that the offer of help be made available at the same time as diagnosis; that is, right at the start of the treatment process. One patient, however, expressed the fear that a navigator might potentially have overtaxed him at such an early stage, as it had been particularly bad for him at the start of his disease. Individually, interviewees expressed their thoughts on how the navigators could be integrated into the existing structures and procedures without there being discrepancies or competency overlaps with other caregivers. For example, one participant expressed the worry that navigators-as an additional person in the care processes-might have different opinions or recommendations than other professional caregivers (eg, nurses or physicians), so that from their point of view there would be a risk of misunderstandings or miscommunication.

\section{DISCUSSION}

The aim of our interview study was to investigate patients' perspectives on navigation, in particular what kind of support people with LC and stroke want from navigators and how a navigation programme should be best integrated into their care trajectory.

Interviewees perceived navigators as potentially valuable, though not all study participants would want to use a navigator themselves, because in their view all of their needs were already being addressed by other resources. Navigators should provide emotional ('being there') and practical (such as with applications, the organisation of care) support, give advice on social care issues and refer to existing support services. A navigator programme should offer patients a consistent contact person who has sufficient time to identify the individual support needs of patients and their informal caregivers as well as already existing support services. The programme, according to study participants, would require a high level of flexibility (for instance, with respect to delivery mode, interaction intervals) depending on patients' preferences, and should be implemented to easily reach patients within existing care structures.

Regarding the tasks to be fulfilled by the navigators, these included many currently unmet needs of patients with LC and stroke, as have been shown in other studies. For example, patients with LC experience unmet needs both throughout their care trajectory and on hospital discharge, and report physical and emotional burdens and even more psychological distress than people with other types of cancer. ${ }^{3-45}$ A qualitative study with people with LC and their informal caregivers in the USA revealed topics like insurance coverage, appointment scheduling and provider-patient communication as organisational barriers to receiving quality care ${ }^{46}$ A qualitative study from Germany showed that patients with LC were uncertain about their role in the coordination of care across healthcare sectors and that they wished to have someone as a coordinator in the treatment process. ${ }^{47}$ This latter finding is in line with our results, where participants expressed the desire for a consistent contact person who would have time for them, and who would be available along their entire care trajectory. Previous studies have reported that patients with stroke are often unaware of the benefits and services available to them and whether or not they can access services again after they have been discharged; patients furthermore reported struggling with bureaucratic procedures related to obtaining health and social services. ${ }^{33}{ }^{48-50}$ Our interview results confirm that currently there seems to be an unmet need in Germany for better social support in outpatient care for patients with chronic diseases such as LC and stroke.

Participants generally preferred their personal networks for care delivery to a navigation programme, even when they had little support from others. They did, however, suggest that people without social networks may be the ones who benefit most from a navigation programme. This is in line with other studies showing the importance of social networks for providing healthcare in the German healthcare context. ${ }^{51}{ }^{52}$ It remains to be investigated if navigation programmes manage to reach those patients without sufficient informal support and if their services are adequately tailored to effectively support them.

Patient navigation has been shown to improve cancerrelated health outcomes and satisfaction, and to decrease concerns and anxiety. ${ }^{53-55}$ In Germany, navigation models for cancer and stroke, as well as for a number of other conditions, are currently being evaluated. ${ }^{56}$ Most of these models are oriented to be target group-specific and disease-specific and have guideline-based treatment as a priority goal. ${ }^{5-59}$ These navigation models often focus mainly on clinical outcomes such as recurrent events or rehospitalisation. To our knowledge, in no cases were the perspectives of patients systematically integrated in the development of these programmes. ${ }^{556}$

In contrast, our qualitative study was conducted in order to help develop a navigation model that is based primarily on the needs and ideas of patients; in other words, our model considers patient needs that have been identified in advance and is thus primarily patient-oriented. For example, the finding that study participants would prefer their contacts with a navigator to be available as and when needed, and not according to a predetermined schedule, is now being considered in the design of our patient navigation programme, to offer a needs-adapted, flexible appointment and contacting concept. Additionally, the desire was expressed in the interviews that relatives and informal caregivers should also receive professional support, because they are also heavily burdened and seem to have unmet needs according to interviewees. Relatives 
and informal caregivers perform an immense body of care for patients with chronic diseases, ranging from nursing care to all tasks involved in care coordination. High burden, psychological distress and perceived helplessness of personal caregivers of patients with chronic diseases has been demonstrated in numerous studies. ${ }^{3360-63}$ Often, this poses additional strains on the interpersonal relationships. Despite the differences in navigator tasks and roles that existing navigation programmes have devised, the common ground is that patient navigators are professionally trained and their roles are aligned with a professional distance in performing their tasks. In Germany's outpatient care system, little assistance is provided to navigate the healthcare system. Existing services such as community-based patient counselling services are rarely centrally coordinated and do not accompany patients and their caregivers along healthcare sectors. Thus, many patients critically depend on informal caregivers in organising their healthcare, and these informal networks have shown to be an important factor for good care delivery in Germany. ${ }^{52}$ However, as the demographic change progresses, the number of patients without functioning and reliable informal care networks increases, and there is a need to establish formal care structures within the medical system that are accessible to these patients in order to avoid significant care gaps. Whether professional patient navigators with formal training in medical and social care issues have the potential to improve care coordination for patients and whether this type of service is effective and cost-effective, remains subject to further empirical investigation.

A strength of the study was that participants were encouraged to express their ideas and wishes as openly and freely as possible in the interviews-without any explanations regarding the concept of patient navigation by the interviewer. The aim was to minimise any influence on the study participants through prior information and details regarding patient navigators, so that they could express their own suggestions and expectations. As a result, participants also mentioned requests for support that do not fit the professional role of healthcare navigators, such as leisure activities. A navigation programme that aims at delivering patient-oriented care has to carefully negotiate the possibilities a healthcare system can offer. For example, the disease may progress leading to strong frustrations and unrealistic expectations to care and thus to requests to the navigator what needs to be done. Other situations, such as unsatisfying personal family relations regarding support, all have the potential to set unrealistic expectations towards navigators. To handle such situations, a navigator training programme should include a communication module as well as a module in which the limits of navigators' tasks are developed during training. Similarly, supervision is often a recommended element.

We sampled according to a purposeful sampling in order to achieve a diverse sample of patients who were likely to have different experiences in the
German healthcare system. Unlike many studies investigating the effectiveness of existing navigation programmes, ${ }^{14} 1925535456$ we placed no restrictions in terms of comorbidities or limitations to a certain disease stage. In our sampling characteristics used to achieve a broad variety of experience, we had not selected study participants based on social support. We only had used married/living with a partner as a selection criterion. However, social support turned up as a crucial characteristic for a potential vulnerability to receive suboptimal care. This in turn, we now argue, is a factor in determining the target group for navigation within the German healthcare system. The sample is not diverse enough to include many people without a support network. It remains open whether and how people who lack social support during their disease trajectory would imagine a navigation programme to look like.

A limitation of our study is that the sample comprises only participants from a single metropolitan region in Germany. Support needs and expectations regarding patient navigation may be different in rural areas and indeed in other countries. However, the selection of patients did take place according to the principle of 'maximum variation' of lived experiences, and thus included participants living in the outskirts of the metropolitan region, which could ameliorate some of this urban focus. Nevertheless, most were treated and lived within the boundaries of the city.

This qualitative interview study shows that LC and stroke are quite similar in terms of expectations about navigation support, despite the differing courses and functional limitations of the two diseases. Navigators certainly need to have disease-specific knowledge in order to be able to provide information and recognise patients' unmet critical care needs, yet the types of needs identified and the types of services needed were very similar for both patient groups and concerned predominantly social, practical and emotional support. Above all, interviewees considered it important that someone would be there for them as a consistent contact person and that the navigation model be designed to be flexible and thus able to focus on individual patient-specific, instead of disease-specific, needs. Both patient groups wished for navigators to proactively approach them and offer support right after diagnosis. Both groups complained about discontinuity and the absence of a fixed contact person in their care trajectory, and they requested support for improved coordination of their care. In Germany, many resources such as community care points, self-help groups, travel and mobility support, home care support, or social counselling exist to support patients to navigate and manage their own healthcare trajectories ${ }^{64}$ However, they are often fragmented and not connected in a visible and optimally accessible manner, especially for patients. Navigators could, therefore, act as a connector between the fragmented, poorly coordinated German healthcare system and the needs of patients with chronic diseases. 


\section{CONCLUSION}

For chronic and complex diseases that have a significant impact on everyday lives, and where a range of therapists and institutions are involved in care-as is the case with LC and stroke-it appears to be less important for navigators to fulfil disease-specific tasks. Rather, they should ensure that patients' more general needs, in relation to social, practical and emotional support, are met in a way that suits patients' individual wishes and goals in relation to their health. This would also include paying attention to the mode, frequency and availability of navigator contacts, and the ways in which navigators would fit into the already-existing individual support system. Following these results, patient navigation programmes could be designed to include generic elements, which should then be adapted to the infrastructure in a particular healthcare region and to the particularities of a specific healthcare system, rather than to disease-specific aspects.

\section{Author affiliations}

${ }^{1}$ Institute of Public Health, Charité - Universitätsmedizin Berlin, corporate member of Freie Universität Berlin, Humboldt-Universität zu Berlin, and Berlin Institute of Health, Berlin, Germany

${ }^{2}$ Institute of Social Medicine and Epidemiology, Brandenburg Medical School Theodor Fontane, Brandenburg/Havel, Germany

${ }^{3}$ Charité Comprehensive Cancer Center, Charité - Universitätsmedizin Berlin, corporate member of Freie Universität Berlin, Humboldt-Universität zu Berlin, and Berlin Institute of Health, Berlin, Germany

${ }^{4}$ Bavarian Health and Food Safety Authority, Bavarian Cancer Registry, Nuremberg, Germany

${ }^{5}$ Dept clinical epidemiology, Leiden University Medical Center, Leiden, The Netherlands

${ }^{6}$ Faculty of Health Sciences, Brandenburg Medical School Theodor Fontane, Neuruppin, Germany

Acknowledgements We would like to thank all patients who participated in the interview study. We also thank Marion Grimberg, Lea Rebecca Minow and Fabienne Janisch for their work as student assistants in the project.

Contributors HF: developed the interview guide; conducted the interviews and the analysis of the data; wrote the manuscript of the paper with input from all authors. UG: supported the recruitment of patients; contributed to the analysis and manuscript (critical revision). KG: contributed to the analysis and manuscript (critical revision). AKD: contributed to the analysis and manuscript. JM-N: conceived the original idea of this study; contributed to the manuscript (critical revision). VM: supported the recruitment of patients; contributed to the analysis and manuscript. BS: Contributed to the manuscript (critical revision). NR: conceived the original idea of this study; contributed to the manuscript (critical revision). $\mathrm{CH}$ : conceived the original idea of this study; contributed to the analysis and manuscript; supervised the study. All authors discussed the results and commented on the manuscript. HF is acting as guarantor for the overall content.

Funding The present work is part of the research consortium 'NAVICARE-Patientoriented health services research'. NAVICARE is funded by the German Ministry of Education and Research (01GY1601).

Competing interests None declared.

Patient consent for publication Consent obtained directly from patient(s)

Ethics approval This study involves human participants and was approved by Ethics committee of the Charité-Universitätsmedizin Berlin, Registration No.: EA2/095/17. Participants gave informed consent to participate in the study before taking part.

Provenance and peer review Not commissioned; externally peer reviewed.

Data availability statement All data relevant to the study are included in the article or uploaded as online supplemental information. Due to data protection restrictions, additional data are not available.
Supplemental material This content has been supplied by the author(s). It has not been vetted by BMJ Publishing Group Limited (BMJ) and may not have been peer-reviewed. Any opinions or recommendations discussed are solely those of the author(s) and are not endorsed by BMJ. BMJ disclaims all liability and responsibility arising from any reliance placed on the content. Where the content includes any translated material, BMJ does not warrant the accuracy and reliability of the translations (including but not limited to local regulations, clinical guidelines, terminology, drug names and drug dosages), and is not responsible for any error and/or omissions arising from translation and adaptation or otherwise.

Open access This is an open access article distributed in accordance with the Creative Commons Attribution Non Commercial (CC BY-NC 4.0) license, which permits others to distribute, remix, adapt, build upon this work non-commercially, and license their derivative works on different terms, provided the original work is properly cited, appropriate credit is given, any changes made indicated, and the use is non-commercial. See: http://creativecommons.org/licenses/by-nc/4.0/.

ORCID iDs

Hella Fügemann http://orcid.org/0000-0001-7920-7351

Christine Holmberg http://orcid.org/0000-0002-8852-4620

\section{REFERENCES}

1 Destatis. Bevölkerung im Wandel: Annahmen und Ergebnisse der 14. koordinierten Bevölkerungsvorausberechnung. [A changing population: assumptions and results of the 14th coordinated population projection]. Wiesbaden: Statistisches Bundesamt, 2019.

2 England K, Azzopardi-Muscat N. Demographic trends and public health in Europe. Eur J Public Health 2017;27:9-13.

3 Health in Germany - Federal Health Reporting Joint Service by RKI and Destatis. Gesundheit in Deutschland: Gesundheitsberichterstattung des Bundes. Gemeinsam getragen von RKI und Destatis. Berlin: Robert Koch-Institut, 2015.

4 WHO. World report on ageing and health. Luxembourg: World Health Organization, 2015.

5 Nelson MLA, McKellar KA, Yi J, et al. Stroke rehabilitation evidence and comorbidity: a systematic scoping review of randomized controlled trials. Top Stroke Rehabil 2017;24:374-80.

6 Osterloh F. Entlassmanagement bereitet Krankenhäusern Probleme. [Discharge management causes problems for hospitals], 2018. Available: https://www.aerzteblatt.de/nachrichten/88826/ Entlassmanagement-bereitet-Krankenhaeusern-Probleme\% 20accessed\%2007.01.2018 [Accessed 4 Mar 2020].

7 Sarfati D, Koczwara B, Jackson C. The impact of comorbidity on cancer and its treatment. CA Cancer J Clin 2016;66:337-50.

8 Schlingensiepen I. Tasche in die Hand, Tschüß vom Krankenhaus [Goodbye from hospital], 2018. Available: https://www.aerztezeitung. de/Wirtschaft/Tasche-in-die-Hand-Tschuess-vom-Krankenhaus231370.html [Accessed 4 Mar 2020].

9 Rosemann T, Neuner-Jehle S, Muheim L. Versorgungsforschung: das richtige Mass an Medizin, zum richtigen Zeitpunkt für den richtigen Patienten [Healthcare Research: the right extent of use of medicine at the right time for the right patient] Therapeutische Umschau 2017;74:827-31.

10 Schoen C, Osborn R, Squires D, et al. New 2011 survey of patients with complex care needs in eleven countries finds that care is often poorly coordinated. Health Aff 2011;30:2437-48.

11 Freund KM, Battaglia TA, Calhoun E, et al. National cancer Institute patient navigation research program: methods, protocol, and measures. Cancer 2008;113:3391-9.

12 Jeyathevan G, Lemonde M, Brathwaite AC. The role of oncology nurse navigators in facilitating continuity of care within the diagnostic phase for adult patients with lung cancer. Can Oncol Nurs $J$ 2017;27:74-80.

13 Kelly E, Ivers N, Zawi R, et al. Patient navigators for people with chronic disease: protocol for a systematic review and meta-analysis. Syst Rev 2015;4:28.

14 Peart A, Lewis V, Brown T, et al. Patient navigators facilitating access to primary care: a scoping review. BMJ Open 2018;8:e019252.

15 Tran K, Delicaet K, Tang T, et al. Perceptions of lung cancer and potential impacts on funding and patient care: a qualitative study. J Cancer Educ 2015;30:62-7.

16 Freeman HP, Muth BJ, Kerner JF. Expanding access to cancer screening and clinical follow-up among the medically underserved. Cancer Pract 1995;3:19-30.

17 Desveaux L, McBrien K, Barnieh L, et al. Mapping variation in intervention design: a systematic review to develop a program theory for patient navigator programs. Syst Rev 2019;8:8. 
18 Freeman HP. The origin, evolution, and principles of patient navigation. Cancer Epidemiol Biomarkers Prev 2012;21:1614-7.

19 Gilbert J, Veazie S, Joines K. Patient navigation models for lung cancer. Rapid evidence product (prepared by Scientific Resource Center under Contract No 290-2017-00003-C) AHRQ Publication No 18(19) EHCO28-EF. Rockville, MD: Agency for Healthcare Research and Quality, 2018.

20 Hendren S, Chin N, Fisher S, et al. Patients' barriers to receipt of cancer care, and factors associated with needing more assistance from a patient navigator. J Natl Med Assoc 2011;103:701-10.

21 Carroll JK, Humiston SG, Meldrum SC, et al. Patients' experiences with navigation for cancer care. Patient Educ Couns 2010;80:241-7.

22 Rohan EA, McDougall R, Townsend JS. An exploration of patient navigation and community health worker activities across national comprehensive cancer control programs. Health Equity 2018;2:366-74

23 Sadler E, Daniel K, Wolfe CDA, et al. Navigating stroke care: the experiences of younger stroke survivors. Disabil Rehabil 2014;36:1911-7.

$24 \mathrm{CHH}$ T, Wilson S, McConigley R. Experiences of cancer patients in a patient navigation program: a qualitative systematic review. JBI Database System Rev Implement Rep 2015;13.

25 van Ee IB, Hagedoorn M, Slaets JPJ, et al. Patient navigation and activation interventions for elderly patients with cancer: a systematic review. Eur J Cancer Care 2017;26 doi:10.1111/ ecc. 12621

26 Hawkins RJ, Jowett A, Godfrey M, et al. Poststroke trajectories: the process of recovery over the longer term following stroke. Glob Qual Nurs Res 2017:4:233339361773020.

27 Lim RBL. End-Of-Life care in patients with advanced lung cancer. Ther Adv Respir Dis 2016;10:455-67.

28 Hammerschmidt S, Wirtz $\mathrm{H}$. Lung cancer: current diagnosis and treatment. Dtsch Arztebl Int 2009;106:809-18.

29 RKI. Fragebogen zur Studie "Gesundheit in Deutschland aktuell": GEDA 2014/2015-EHIS [Questionnaire for the study: German health update (GEDA)]. J Health Monit 2017;2:105-35.

30 Crichton SL, Bray BD, McKevitt C, et al. Patient outcomes up to 15 years after stroke: survival, disability, quality of life, cognition and mental health. J Neurol Neurosurg Psychiatry 2016;87:1091-8.

31 Lutz BJ, Ellen Young M, Cox KJ, et al. The crisis of stroke: experiences of patients and their family caregivers. Top Stroke Rehabil 2011:18:786-97.

32 Maguire R, Papadopoulou C, Kotronoulas G, et al. A systematic review of supportive care needs of people living with lung cancer. Eur J Oncol Nurs 2013;17:449-64.

33 Padberg I, Knispel P, Zöllner S, et al. Social work after stroke: identifying demand for support by recording stroke patients and carers' needs in different phases after stroke. BMC Neurol 2016;16:111-11.

34 Sandelowski M. Whatever happened to qualitative description? Res Nurs Health 2000;23:334-40.

35 Sandelowski M. What's in a name? qualitative description revisited. Res Nurs Health 2010;33:77-84.

36 Bradshaw C, Atkinson S, Doody O. Employing a qualitative description approach in health care research. Glob Qual Nurs Res 2017; 4:2333393617742282.

37 Vaismoradi M, Turunen H, Bondas T. Content analysis and thematic analysis: implications for conducting a qualitative descriptive study. Nurs Health Sci 2013;15:398-405.

38 Braun V, Clarke V. Using thematic analysis in psychology. Qual Res Psychol 2006;3:77-101.

39 Brown NMK, Lui C-W, Robinson PC, et al. Supportive care needs and preferences of lung cancer patients: a semi-structured qualitative interview study. Support Care Cancer 2015;23:1533-9.

40 Giuliani ME, Milne RA, Puts M, et al. The prevalence and nature of supportive care needs in lung cancer patients. Curr Oncol 2016;23:258-65.

41 Hoffman AJ, Brintnall RA, von Eye A, et al. The voice of postsurgical lung cancer patients regarding supportive care needs. Lung Cancer 2014;5:21-31.

42 Lövgren M, Tishelman C, Sprangers M, et al. Symptoms and problems with functioning among women and men with inoperable lung cancer-a longitudinal study. Lung Cancer 2008;60:113-24.

43 Stanze H, Schneider N, Nauck F, et al. "I can't get it into my head that I have cancer..."-A qualitative interview study on needs of patients with lung cancer. PLoS One 2019;14:e0216778.
44 Villalobos M, Coulibaly K, Krug K, et al. A longitudinal communication approach in advanced lung cancer: a qualitative study of patients', relatives' and staff's perspectives. Eur J Cancer Care 2018;27:e12794.

45 Zabora J, BrintzenhofeSzoc K, Curbow B, et al. The prevalence of psychological distress by cancer site. Psychooncology 2001;10:19-28.

46 Kedia S, Ward K, Digney SA. Qualitative assessment of organizational barriers to optimal lung cancer care in a community hospital setting in the United States. J Community Support Oncol 2018;16:e89-96.

47 Bossert J, Forstner J, Villalobos M, et al. What patients with lung cancer with comorbidity tell us about interprofessional collaborative care across healthcare sectors: qualitative interview study. BMJ Open 2020;10:e036495.

48 Chen T, Zhang B, Deng Y, et al. Long-term unmet needs after stroke: systematic review of evidence from survey studies. BMJ Open 2019;9:e028137.

49 Finch E, Foster M, Fleming J, et al. Exploring changing needs following minor stroke. Health Soc Care Community 2020;28:347-56.

50 Lehnerer S, Hotter B, Padberg I, et al. Social work support and unmet social needs in life after stroke: a cross-sectional exploratory study. BMC Neurol 2019;19:220.

51 Sparla A, Flach-Vorgang S, Villalobos M, et al. Individual difficulties and resources - a qualitative analysis in patients with advanced lung cancer and their relatives. Patient Prefer Adherence 2016;10:2021-9.

52 Schindel D, Schneider A, Grittner U, et al. Quality of life after stroke rehabilitation discharge: a 12-month longitudinal study. Disabil Rehabil 2021:43:2332-41.

53 Ferrante JM, Chen P-H, Kim S. The effect of patient navigation on time to diagnosis, anxiety, and satisfaction in urban minority women with abnormal mammograms: a randomized controlled trial. J Urban Health 2008;85:114-24.

54 Fillion L, de Serres M, Cook S, et al. Professional patient navigation in head and neck cancer. Semin Oncol Nurs 2009;25:212-21.

55 Wells KJ, Battaglia TA, Dudley DJ, et al. Patient navigation: state of the art or is it science? Cancer 2008;113:1999-2010.

56 Braeseke G, Huster S, Pflug C. Studie zum Versorgungsmanagement durch Patientenlotsen. [Study on care management by patient navigators] Abschlussbericht für die Beauftragte der Bundesregierung für die Belange der Patientinnen und Patienten. Gesundheit, Mobilität, Bildung]. Berlin: IGES Institut, 2018.

57 STROKE OWL. Unterstützende Nachsorge durch SchlaganfallLotsen: Projekt für koordiniert-vernetzte Versorgung nach Schlaganfall. [STROKE OWL - Supportive aftercare by stroke pilots: Project for coordinated care after stroke]. Gütersloh: Stiftung Deutsche Schlaganfall-Hilfe. Available: https://stroke-owl.de/de/ startseite/ [Accessed 4 Mar 2020].

58 Porzig R, Neugebauer S, Heckmann T, et al. Evaluation of a cancer patient navigation program ("Onkolotse") in terms of hospitalization rates, resource use and healthcare costs: rationale and design of a randomized, controlled study. BMC Health Serv Res 2018;18:413.

59 Frick J, Schindel D, Gebert P, et al. Improving quality of life in cancer patients through higher participation and health literacy: study protocol for evaluating the oncological social care project (OSCAR) BMC Health Serv Res 2019;19:754-54.

60 Hempler I, Woitha K, Thielhorn U, et al. Post-stroke care after medical rehabilitation in Germany: a systematic literature review of the current provision of stroke patients. BMC Health Serv Res 2018; $18: 468$

61 Krishnasamy M, Wells M, Wilkie E. Patients and carer experiences of care provision after a diagnosis of lung cancer in Scotland. Support Care Cancer 2007:15:327-32.

62 Pindus DM, Mullis R, Lim L, et al. Stroke survivors' and informal caregivers' experiences of primary care and community healthcare services - A systematic review and meta-ethnography. PLoS One 2018;13:e0192533.

63 Doucet S, Curran JA, Breneol S, et al. Programmes to support transitions in care for children and youth with complex care needs and their families: a scoping review protocol. BMJ Open 2020;10:e033978.

64 Gödde K, Fügemann H, Müller-Nordhorn J. Strukturierte Erfassung von Unterstützungsangeboten für Lungenkrebs- und Schlaganfallbetroffene in Berlin. [Structured Collection of Data on Support Offers for Lung Cancer and Stroke Patients in Berlin] Das Gesundheitswesen, 2020. 